$$
\text { CoNF-950956-4 }
$$

GA-A22165

\title{
VANADIUM ALLOYS FOR THE RADIATIVE DIVERTOR PROGRAM OF DIII-D
}

by

J.P. SMITH, W.R. JOHNSON, R.D. STAMBAUGH, P.W. TRESTER, D. SMITH, and E. BLOOM

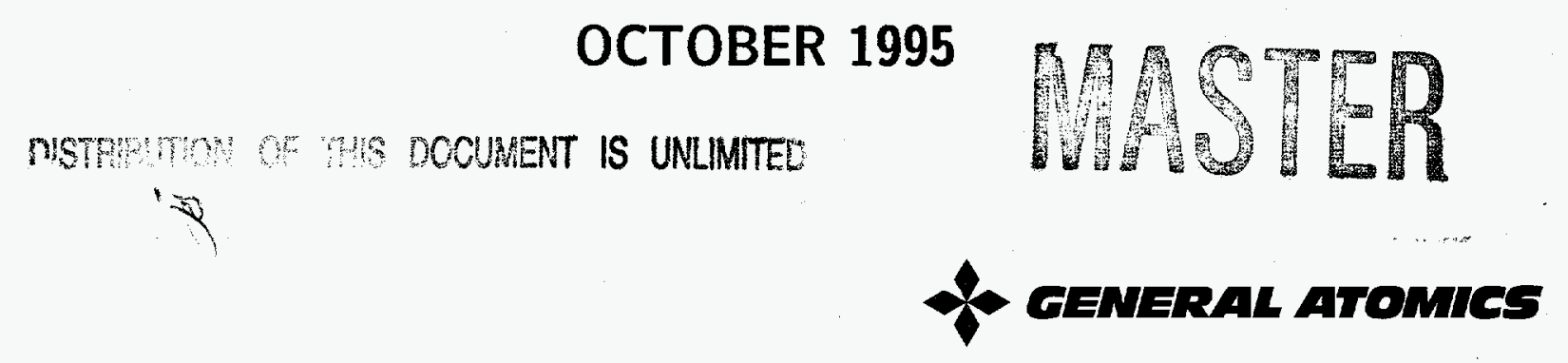


DISCLAIMER

This report was prepared as an account of work sponsored by an agency of the United States Government. Neither the United States Government nor any agency thereof, nor any of their employees, makes any warranty, express or implied, or assumes any legal liability or responsibility for the accuracy, completeness, or usefulness of any information, apparatus, product, or process disclosed, or represents that its use would not infringe privately owned rights. Reference herein to any specific commercial product, process, or service by trade name, trademark, manufacturer, or otherwise, does not necessarily constitute or imply its endorsement, recommendation, or favoring by the United States Government or any agency thereof. The views and opinions of authors expressed herein do not necessarily state or reflect those of the United States Government or any agency thereof. 


\section{DISCLAIMER}

Portions of this document may be illegible in electronic image products. Images are produced from the best available original document. 


\section{VANADIUM ALLOYS FOR THE RADIATIVE DIVERTOR PROGRAM OF DIII-D}

by

J.P. SMITH, W.R. JOHNSON, R.D. STAMBAUGH, P.W. TRESTER, D. SMITH, ${ }^{*}$ and E. BLOOM ${ }^{\dagger}$

This is a preprint of a paper presented at the 16th IEEE/NPSS Symposium on Fusion Engineering, September 30-October 5, 1995, Champaign, Illinois, and to be printed in the Proceedings.

Work supported by

U.S. Department of Energy Contracts

DE-AC03-89ER51114, W-31-109-ENG-38, and DE-AC05-840R21400

*Argonne National Laboratory

† Oak Ridge National Laboratory

GENERAL ATOMICS PROJECT 3990

OCTOBER 1995 


\title{
Vanadium Alloys For The Radiative Divertor Program of DIII-D*
}

\author{
J.P. Smith, W.R. Johnson, R.D. Stambaugh, P.W. Trester, D. Smith, ${ }^{a}$ and E. Bloom ${ }^{b}$ \\ General Atomics, P.O. Box 85608, San Diego, California 92186-9784 \\ aArgonne National Laboratory, Argonne, Illinois \\ b Oak Ridge National Laboratoary, Oak Ridge, Tennessee
}

\begin{abstract}
Vanadium alloys provide an attractive solution for fusion power plants as they exhibit a potential for low environmental impact due to low level of activation from neutron fluence and a relatively short half-life. They also have attractive material properties for use in a reactor. General Atomics along with Argonne National Laboratory (ANL) and Oak Ridge National Laboratory (ORNL), has developed a plan to utilize vanadium alloys as part of the Radiative Divertor Project (RDP) modification for the DIII-D tokamak (1). The goal for using vanadium alloys is to provide a meaningful step towards developing advanced materials for fusion power applications by demonstrating the in-service behavior of a vanadium alloy ( $\mathrm{V}-4 \mathrm{Cr}-4 \mathrm{Ti})$ in a tokamak in conjunction with developing essential fabrication technology for the manufacture of full-scale vanadium alloy components. A phased approach towards utilizing vanadium in DIII-D is being used starting with small coupons and samples, advancing to a small component, and finally a portion of the new double-null, slotted divertor will be fabricated from vanadium alloy product forms. A major portion of the program is research and development to support fabrication and resolve key issues related to environmental effects.
\end{abstract}

\section{INTRODUCTION}

Fusion is an attractive alternative energy source when coupled with its inherent potential for low impact on the environment. However, it is necessary to utilize low activation materials in fusion systems in order to realize this potential. Many materials which have the possibility for minimum environmental impact have been studied and tested to obtain candidate alloys with attractive physical and mechanical properties for fusion systems. One of the most promising candidate materials is vanadium-based alloys. This refractory metal alloy has high strength at high temperature, excellent resistance to neutron embrittlement, and a low ductile-to-brittle transition temperature, in addition to its low activation. Vanadium alloys also have good ductility lending themselves to standard conversion and manufacturing processes. To date, a basic understanding of the behavior of vanadium alloys has been achieved through extensive research and development [1], but much more work is required to develop processing "know-how" and engineering data necessary for component design.

Utilizing vanadium in DIII-D provides the opportunity to make a meaningful step in the development and use of low activation materials in two ways: 1 ) begin the process of developing information for the fabrication of full-scale vanadium alloy components, and 2) demonstrate the behavior of a vanadium alloy in a representative high heat flux tokamak environment

The program will be implemented in three phases. The first phase is the exposure of small coupon samples in DIII-D including positions in the vessel floor and in the existing divertor baffle plenum. A small vanadium alloy component will follow and be operated in conjunction with existing divertor hardware. Lastly, a portion of the upper of the divertor structure will be fabricated from vanadium alloy as part of the Radiative Divertor Project upgrade. Necessary R\&D efforts to support fabrication development and to resolve key issues related to the environmental effects will be performed as part of the program.

DIII-D, a deuterium-deuterium experiment, will test the mechanical functions of the vanadium in the tokamak environment without significant neutron irradiation, eliminating irradiation behavior of the material as a factor in the current design and manufacture. This makes the inservice demands and thus the risk, small. Hands on maintenance of the components will always be possible with a vent of the machine. Should any problem with the vanadium structure develop, it can be isolated from the rest of the coolant system, and the DIII-D research program can continue, running single-null divertor plasmas until the next torus vent when repairs can be implemented. The vanadium exposure in DIII-D is expected to yield an early confirmation that the alloys are compatible with the tokamak operating environment particularly with respect to potentially embrittling impurities such as hydrogen and oxygen. In addition, the development of the materials processing methods for the components will be a significant initial step in the qualification for future application in fusion systems.

The execution of this plan is a joint effort by General Atomics, the DIII-D program and DOE materials program participants, primarily ANL and ORNL. A description of the three phases and accompanying $R \& D$ program follows.

\section{PHASE 1: SPECIMENS AND COUPONS}

The first phase of the vanadium program is the installation of coupons and specimens in DIII-D to measure the effect of thetokamak environment, if any, on the vanadium alloys. Long term (>6 months) exposures started in March of 1995 with the installation of five Charpy V-notch impact and five

\footnotetext{
*Work supported by the U.S. Department of Energy under Contract Nos. DE-AC03-89ER51114, W-31-109-ENG-38, and DE-AC05-84OR21400, and GA. corporate funding.
} 
tensile specimens of vanadium alloy ( $\mathrm{V}-4 \mathrm{Cr}-4 \mathrm{Ti})$ in DIII-D divertor baffle region (Fig. 1). ANL supplied the samples, and General Atomics provided the design and fabrication of the hardware for retaining the samples. The specimen environment is being monitored during various stages of DIII-D operation (e.g. baking discharge cleaning, boronization, plasma discharges, etc.). These samples will be removed at the next major vent, scheduled for the end of 1995. Testing of the specimens will be performed by ANL and results compared to a control set of samples to look at degradation of properties during the exposure. Metallographic examination will follow the testing to evaluate hydrogen, oxygen and other impurity pick-up.

In parallel, other vanadium samples have been prepared and exposed in the divertor target region utilizing the DIII-D Divertor Material Exposure System (DiMES). Usage of DiMES allows for a short term exposure and subsequent retraction of a material sample or specimen. The first exposure in DiMES consisted of a vanadium alloy disc which saw the initial baking and cleaning of DIII-D after the March 1995 vent. It is believed that a post-vent bake cycle is potentially one of the most severe environmental conditions for the vanadium alloy with relatively high concentrations of impurities present which may lead to embrittlement of the material. The initial exposure was qualitative but indicates impurity pickup in the vanadium alloy specimen. Testing of the sample is ongoing. Additional exposures of Charpy V-notch impact specimens to a similar baking cycle have recently been completed and are awaiting testing. Additional DiMES exposures are planned to evaluate the effects of other DIII-D environmental conditions (e.g., discharge cleaning, boronization, etc.), including possible divertor plasma strikes.

\section{PHASE 2: SMALL COMPONENT}

The second step of the program is to install a small component which will operate in conjunction with the existing DIII-D Advanced Divertor. A single radiatively-cooled structural plate or a small water-cooled component will be designed and fabricated. The purpose of this phase is to make a small workable component and operate the machine with it in the tokamak environment before installation of the larger Phase 3 components. The component will be installed during the DIII-D vent scheduled for late CY95. Various fabrication

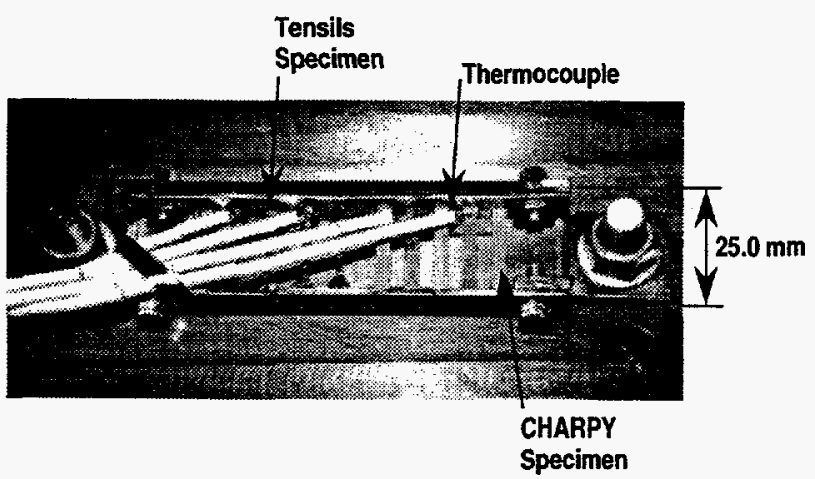

Fig. 1. Long-term vanadium tensile and Charpy V-notch specimens installed in DIII-D. processes are being considered for the component including bending, welding, and standard machining operations. Cleaning and heat treating will also be used in the preparation of the panel. Gas-Tungsten Arc, resistance, or electron beam welding are candidate weld processes for making the component. The component will be removed in the fall of 1996 when the machine is vented for the installation of the RDP structure. After removal, metallurgical analyses and property measurements will be performed on samples excised from the component. Information from this test could reveal any potential problems for the Phase 3 vanadium hardware prior to the final installation.

\section{PHASE 3: RADIATIVE DIVERTOR PROGRAM}

The third and final phase for the utilization of vanadium alloy in DIII-D will be to design, manufacture, and install a portion of the upper divertor structure for the Radiative Divertor using vanadium alloy (Fig. 2). For the balance of the system, Inconel 625 is the structural material [2]. The vanadium portion of the structure will consist of watercooled panels, toroidally continuous, and will have inertially cooled graphite tiles mechanically attached to their surfaces. During machine operation, the panels will be water cooled and will experience a maximum temperature of $60^{\circ} \mathrm{C}$. The entire vacuum vessel and internal components will be baked to $\sim 400^{\circ} \mathrm{C}$ to provide high quality vacuum conditions for operations. During this bake, hot air replaces the water in the coolant channels and eddy currents are driven in the structure to provide heating. Oxidation of vanadium in air at $400^{\circ} \mathrm{C}$ was a concern for the design, but preliminary test results [3] have revealed that oxidation of the vanadium is minimal and this baking cycle should not present a problem. Support for the panels to the vacuum vessel wall is provided by bolted Inconel 718 brackets. These supports will provide the required strength for reacting disruption loads and the flexibility for accommodating differential thermal growth with respect to the Inconel vacuum vessel during baking.

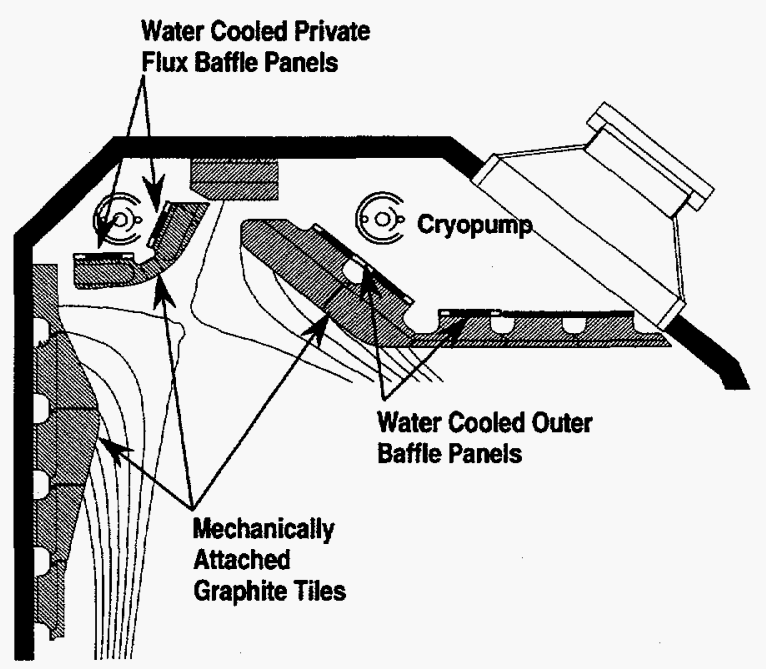

Fig. 2. Vanadium alloy components of Radiative Divertor will be the water-cooled panels of either the private flux baffle or outer baffle. 
Structural properties of $\mathrm{V}-4 \mathrm{Cr}-4 \mathrm{Ti}$ alloy are similar to Inconel 625. A comparison of the properties is seen in Table I. The primary differences are in the ultimate strength, elastic modulus, and electrical resistivity. The yield strength of the two alloys are very similar, but the lower ultimate strength of vanadium alloy lowers the design stress allowable for the material. The lower modulus will increase the deflections of the panels. Analysis is ongoing to for the development of the design with these properties. Due to the lower electrical resistivity of vanadium alloys as compared to Inconel, the toroidal currents flowing in the panels during disruption will be approximately five times larger. This increases the forces from the toroidal currents to be close to the value of the loads from halo currents. Analysis is ongoing for the design in this area as well.

Table I

Comparison of Vanadium Properties to Other PFC Materials

\begin{tabular}{llcc}
\hline Property & Units & $\mathrm{V}-4 \mathrm{Cr}-4 \mathrm{Ti}$ & Inconel \\
\hline Density & $\mathrm{g} / \mathrm{cc}$ & 6.1 & 8.44 \\
Specific Heat & $\mathrm{kJ} / \mathrm{kg}-{ }^{\circ} \mathrm{C}$ & 0.52 & 0.41 \\
Coefficient of Thermal & $10^{-6} /{ }^{\circ} \mathrm{C}$ & 10 & 15.8 \\
Expansion $\left(0-550^{\circ} \mathrm{C}\right)$ & $\mu \Omega-\mathrm{cm}$ & 27 & 125 \\
Resistivity & $\mathrm{W} / \mathrm{m} \mathrm{K}$ & 31.3 & 10 \\
Thermal Conductivity & $\mathrm{ksi}$ & 77 & 124 \\
Ultimate Strength & $\mathrm{ksi}$ & 54.2 & 53 \\
Yield Strength & $\mathrm{ks}$ & 19 & 30 \\
Elastic Modulus & $\mathrm{msi}$ & 28 & 59 \\
Total Elongation & $\%$ & 0.36 & 0.3 \\
Poisson's Ratio & & & \\
\hline
\end{tabular}

The panels will be made in 60 deg. segments and fabricated of sandwich construction from two $0.4 \mathrm{~cm}$ plates, each containing a $0.15 \mathrm{~cm}$ deep coolant channel milled into its face. Resistance seam welding will be used to join the panel perimeter to create a leak tight seal. The segments will be assembled and bolted together inside the tokamak. Water connections will be made after installation of the segments by welding of specially-designed manifolds. Following service in DIII-D for several years, the Phase 3 vanadium components will be removed. Examination, property measurements, and metallurgical analyses will be performed.

\section{MANUFACTURING DEVELOPMENT}

Development of manufacturing methods is key to the success of this project and a significant amount of research and development is being and will continue to be performed. To date only research quantities and one $500 \mathrm{~kg}$ ingot of vanadium alloys have been produced in the U.S. Conversion of these melts has been in small pieces and quantities. Plates large enough for the RDP panels will require a conversion scale up near a factor of 5 in individual plate size and even more in terms of total quantity converted. Basic engineering design properties have not been measured, particularly as a function of temperature and product form. The Radiative
Divertor structure will require many metal/metal joints. No production welding and only small amounts of research welding have been performed on vanadium and its alloys. Welding development is therefore a key area of study for the project. Cleaning and heat treatment processes and the environmental requirements for these processes will require development.

The development of production capabilities, particularly conversion of ingot into product forms (plate, sheet, rod, and tubing) is essential to the program. General Atomics has recently successfully produced a $0.4 \mathrm{~m}$ length of $\emptyset 20 \mathrm{~mm}$ x $2 \mathrm{~mm}$ wall vanadium alloy tubing.A specification for the production of $\mathrm{V}-4 \mathrm{Cr}-4 \mathrm{Ti}$ alloy and conversion into plate and rod material for the RDP structure has been written. Specification for the production of tubing is also complete. The material for the RDP project has been ordered, and processing of the material has been initiated by Teledyne Wah Chang Albany (TWCA). Plate, rod and possibly tubing will be the final converted product forms. The alloy content and its impurities, are being carefully monitored throughout the production processes. The required quantity of product forms requires an ingot of approximately $800 \mathrm{~kg}$, the largest single ingot of vanadium alloy ever produced.

Testing of mechanical properties critical to the design is on going for this alloy. Properties being measured include tensile strength, modulus of elasticity, and fatigue strength over the DIII-D operating temperature range, and as a function of product form. For example, measurements have shown that cross rolling of sheet and plate is required to maintain ductility of the material in both the longitudinal and transverse rolling directions [4]. This cross rolling requirement is included in the specification for production of RDP material. The baseline property measurement is being performed jointly by ANL and ORNL. The vanadium alloy material being used for performing these tests is a portion of the $500 \mathrm{~kg}$ heat of $\mathrm{V}-4 \mathrm{Cr}-4 \mathrm{Ti}$ alloy produced for ANL by TWCA in 1994, and it is the baseline for the RDP material.

Many welding processes are being considered and developed for the manufacture of the RDP components. These include resistance seam, electrodischarge (stud), inertial, GTA, and electron beam welds. The potential applications of these welds can be seen in Fig. 3. The primary concern for any of the welding processes is the pick-up of embrittling impurities while at the welding temperature or resolidification of the melt pool. This leads to loss of ductility and potential source of failure in the material. Typically refractory metals are welded or heated in tightly controlled atmospheres to limit this detrimental effect.

Resistance seam welding is considered as the primary option to form the closure weld in the RDP water-cooled panels. Up to 1500 linear inches of vanadium resistance seam welding will be utilized in the manufacture of the panels. Initial spot weld trials performed on sheet in air have shown only a small increase in hardness in the weld or heat affected zone and is encouraging for the possibility of performing the weld in air. Continuation of spot and seam weld trials are planned to study the weld properties for vanadium alloys. Industrial companies with scam welding experience on refractory 


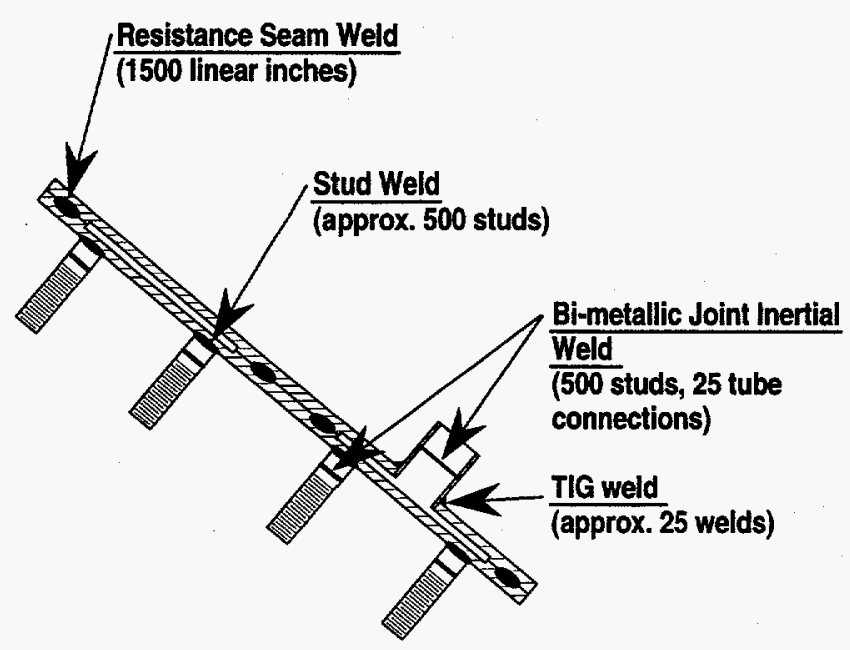

Fig. 3. The different types and locations of welds within the vanadium portion of the Radiative Divertor.

cmetals have been identified and are performing some additional weld tests. Metallographic and mechanical property data will be obtained as part of the weld sample evaluation.

Presently, Inconel weld studs are routinely used in DIII-D for fastening structures and tiles to the vessel walls and stud (electrodischarge) welding is being examined as the attachment method for the approximately 500 vanadium studs to the vanadium panels. Weld studs are being utilized rather than through-panel bolts to eliminate drilling holes through the water channels and creating potential water leaks. Weld evaluation tests will be performed both in air and inert environments to determine an appropriate welding atmosphere. Tensile and torque tests, along with metallographic analyses, will be performed on the test coupons to select appropriate welding parameters. General Atomics technicians will be trained and qualified in the necessary processes.

Inertial or spin welding has been selected as an attractive option for creation of dissimilar (bimetallic) metal joints in the RDP design. A bimetallic joint between vanadium alloy and Inconel or other candidate material may be utilized in two different locations. First, if the vanadium alloy proves to be an unacceptable fastener material due to a tendency to gall, inability to machine quality threads, or lacking thread strength, a bimetallic joint will be created between a fastener (thread zone) material and a vanadium alloy shaft for the stud. This stud can then be welded to the vanadium alloy plates as in Fig. 3. Second, a bimetallic joint may be used in the water lines to connect a stainless steel or Inconel stub to vanadium alloy tubing. This joint will allow the use of standard welding processes for making field welds inside the DIII-D vessel, rather than creating a glove box environment for field welds to protect the material from impurities while at temperature. Candidate materials for the bimetallic joints have been identified and companies with experience in joining refractory metals to other alloys are performing tests on several material couples, including stainless steel, Inconel, and titanium. Mechanical property measurements and metallographic analyses will be performed on these weld samples. Inertial welding is considered as back-up option for the 500 stud/plate and 24 water tube/panel connections should feasibility of other welding processes prove to be difficult.

To join vanadium to itself, GTA welding is considered for the RDP structure in two potential areas: the connection of tubing to the flat water-cooled panels and vanadium alloy field welds. ORNL has been performing weld trials on both $\mathrm{V}-4 \mathrm{Cr}-4 \mathrm{Ti}$ and $\mathrm{V}-5 \mathrm{Cr}-5 \mathrm{Ti}$ alloy material. Although preliminary welds have exhibited a tendency toward embrittlement (upward shift in ductile-brittle transition temperature), addi tional studies have shown that the embrittlement can be diminished by post-weld heat treatment. In addition, some loss of ductility in the weld area may be acceptable for the design and operation of the panels. Stress analyses coupled with additional test results are planned to address the feasibility of utilizing GTA welding for the RDP panels.

Electron beam (EB) welding has been proposed in the fabrication of the Phase 2 vanadium alloy component and as a back-up for resistance seam welding of the RDP watercooled panels. EB welding was not considered as the prime candidate process for the panels because of concerns about global weld distortion and shrinkage of the panels as compared to resistance seam welding. Typically EB welding is considered a low heat input welding process with minimal weld distortion, but to react the shear loads between the sheets of the panels, a large amount of weld area is required, leading to larger weld distortions. ORNL and ANL have been performing electron beam welds of vanadium alloys and work continues on these efforts to study weld properties, settings required, and the environmental requirements for welding.

Fabrication processes such as machining, cutting, forming and cleaning/heat treating are under study. Each of these steps is a potential contamination or impurity source as experience with most refractory metal alloys has shown. Specifications will be written as required to guarantee clean, non contaminated components.

\section{CONCLUSION}

A program is in progress to begin the qualification of a low activation material, vanadium alloys, for fusion applications to demonstrate the tokamak compatibility and fabricability of vanadium alloys. Material production has started on the largest quantity of vanadium alloy ever produced to be used in the manufacture of components for the DIII-D Radiative Divertor Project modification. All preliminary results point toward a successful implementation of vanadium in the RDP program. The installation of the vanadium alloy components will take place late in the 1996 calendar year.

\section{REFERENCES}

[1] D.L. Smith, et al, Fusion Engineering and Design 29 (1995) pg. 399-410

[2] J.P. Smith, et al., "Engineering design of a Radiative Divertor for DIII-D," this conference.

[3] Private communication with J. DeSteffano, ORNL, work not yet published.

[4] Private communication with $\mathrm{H}$. Chung, ANL, work not yet published. 